\title{
FORMAÇÃO DO PREÇO DE HONORÁRIOS CONTÁBEIS EM TANGARÁ DA SERRA-MT: ANÁLISE DOS COMPONENTES DO PREÇO
}

\author{
Adrielli Sommer Dallabona ${ }^{1}$ \\ Laércio Juarez Melz ${ }^{2}$ \\ Josiane Silva Costa dos Santos ${ }^{3}$ \\ Edineia Souza Nunes ${ }^{4}$
}

\section{RESUMO}

A formação do preço de honorários contábeis é de suma importância para a saúde financeira dos escritórios, pois eles determinam a sobrevivência ou não destes no mercado. Neste sentido, o presente estudo teve como objetivo identificar os critérios utilizados pelos escritórios contábeis para a formação do preço de seus honorários. Em termos metodológicos, o trabalho se caracteriza como descritivo, qualitativo e exploratório. A amostra compreende os donos e/ou sócios de escritórios do município de Tangará da Serra - Mato Grosso. O problema da pesquisa concentra-se na questão: Quais os fatores considerados na formação dos preços de honorários contábeis em Tangará da Serra-MT? Os resultados da pesquisa apontaram que o fator que mais influencia na escolha dos preços é a relevância, o vulto, a complexidade e a dificuldade do serviço a executar. Diante do exposto, e com base nos dados levantados, conclui-se que, dada a relevância de cada serviço prestado pelos escritórios de contabilidade, o fator que se destaca como determinante é a complexidade e dificuldade de cada serviço.

Palavras-chave: Prestação de serviços. Preços de venda. Escritórios contábeis. Contabilidade de Custos.

\section{INTRODUÇÃO}

A contabilidade é de grande importância, pois fornece dados que demonstram a saúde financeira e econômica da organização, para que o empresário consiga, de forma concreta, tomar decisões visando o crescimento financeiro e social de sua empresa.

Determinar o preço de venda de bens ou serviços é fundamental para qualquer empresa, independentemente de seu ramo de atividade ou de seu porte, pois é ele quem determina a sobrevivência e o crescimento da mesma no mercado.

Sobre a dificuldade e ao papel do contador na formação dos preços, Hansen e Mowen (2001, p. 655) descrevem que: "uma das decisões mais difíceis que uma empresa enfrenta é a precificação. O contador é, com frequência, a fonte primária que a empresa procura quando

\footnotetext{
1 Acadêmica do curso de Ciências Contábeis da UNEMAT - Campus de Tangará da Serra, e-mail: adrielli_sommer@hotmail.com

${ }^{2}$ Mestre em Engenharia de Produção (UFSCar), Professor do curso de Ciências Contábeis da UNEMAT Campus de Tangará da Serra, e-mail: laercio@unemat.br

${ }^{3}$ Professora do curso de Ciências Contábeis da UNEMAT - Campus de Tangará da Serra.

${ }^{4}$ Professora do curso de Ciências Contábeis da UNEMAT - Campus de Tangará da Serra.
} 
Formação do preço de honorários contábeis em Tangará da Serra-MT: análise dos componentes do preço Adrielli Sommer Dallabona, Laércio Juarez Melz, Josiane Silva Costa dos Santos, Edineia Souza Nunes

precisa de dados financeiros, sejam essas informações relativas a custos ou preços." Entendese por preço a avaliação em dinheiro ou valor assimilável de uma mercadoria ou de um serviço.

Os serviços prestados por empresas devem, principalmente, oferecer segurança, estar dentro das normas legais, superar as expectativas dos clientes e cumprir rigorosamente os prazos previstos.

Diante do exposto, observando a importância que a contabilidade tem para as empresas, e a importância da formação do preço de venda para as mesmas, justifica-se a pesquisa, cujo objetivo geral consiste em identificar e comparar os critérios de formação de honorários contábeis em escritórios contábeis no município de Tangará da Serra-MT. Os objetivos específicos consistem em: a) Caracterizar a amostra; b) Levantar fatores influenciadores dos preços de serviços; c) Apontar os fatores caracterizados como mais importantes na formação de honorários contábeis; d) Comparar as características e os critérios estabelecidos pelos escritórios para formar o preço de seus Honorários. O problema da pesquisa concentra-se na seguinte questão: Quais os fatores considerados na formação dos preços de honorários contábeis em Tangará da Serra-MT?

\section{REFERENCIAL TEÓRICO}

Nesta seção será abordado o embasamento teórico, e para que haja um melhor entendimento, o mesmo foi dividido em cinco tópicos: Prestação de Serviços Contábeis, Representação da Classe Contábil, Convenção Coletiva de Trabalho 2012/2013, Honorários Contábeis e Formação do Preço.

\subsection{Prestação de Serviços}

Contador é o diplomado em curso superior de Ciências Contábeis, bem como aquele que, por força maior de lei, lhe é equiparado, com registro nessa categoria no Conselho Regional de Contabilidade - CRC; e Técnico em Contabilidade é o diplomado em curso com nível técnico na área contábil, com registro em CRC nessa categoria (ROCHA, 2005).

De acordo com o Conselho Federal de Contabilidade (CFC), em sua Resolução Nº. 1373/11, de 08 de dezembro de 2011 (que revoga a Resolução No . 853/99, de 28 de julho de 1999), "somente poderão exercer a profissão após a regular conclusão do respectivo curso, 
Formação do preço de honorários contábeis em Tangará da Serra-MT: análise dos componentes do preço Adrielli Sommer Dallabona, Laércio Juarez Melz, Josiane Silva Costa dos Santos, Edineia Souza Nunes

reconhecido pelo Ministério da Educação, aprovação em Exame de Suficiência e registro no Conselho Regional de Contabilidade a que estiverem sujeitos" (CFC, 2011).

Conforme Reis e Silva (2007, p. 11):

\begin{abstract}
O profissional da área contábil no século XXI deve ter um conhecimento vasto e qualificado. Diante das novas necessidades do mercado, que dispõe de muitas informações em reduzido espaço de tempo, e devido às inovações tecnológicas, é exigido do profissional ética, agilidade diante dos problemas, auxílio na tomada de decisões, além de manter-se atualizado continuamente. Para isso os Conselhos Regionais e o Conselho Federal de Contabilidade atuam realizando cursos, seminários e fóruns.
\end{abstract}

A Contabilidade se fundamenta em princípios, leis e outras normas decorrentes das relações sociais entre pessoas, empresas e instituições em geral, sendo, portanto, vinculada à área das ciências sociais aplicadas; e a regulamentação da profissão contábil ocorreu com a edição do Decreto-Lei №. 9.295/46, dando aos Conselhos de Contabilidade a estrutura federativa, colocando os Conselhos Regionais de Contabilidade subordinados ao Conselho Federal de Contabilidade (ROCHA, 2005).

A prestação de serviços é regulada pelo Código Civil, nos artigos 593 a 609, em contrato pelo qual um dos contratantes, o prestador, se compromete a prestar serviços que o outro, denominado contratante, se obriga a remunerar (BRASIL, 2002).

Segundo Rocha (2005, p. 4), "as atividades profissionais podem ser exercidas na forma de prestação de serviços, com ou sem vínculo empregatício, bem como na modalidade empresarial, em que o empreendedor articula os fatores de produção na busca da fabricação, comercialização ou prestação de serviços".

O Profissional da Contabilidade poderá transferir o contrato de serviços a seu cargo a outro profissional, com a anuência do cliente, sempre por escrito, de acordo com as normas expedidas pelo Conselho Federal de Contabilidade (Código de Ética Profissional do Contador, Capítulo III, Art. $7^{\circ}$.).

Duffecke (2007, p. 3) descreve que "a finalidade principal de um contrato de prestação de serviços contábeis é a de estabelecer as cláusulas que regerá a relação entre os contratantes, sendo objetiva, clara e transparente, de forma a se comprovar os limites e a extensão da respectiva responsabilidade técnica".

De acordo com o CFC (2003), Art. 2. ${ }^{\circ}$ o Contrato de Prestação de Serviços deve conter, no mínimo, a identificação das partes contratantes; a relação dos serviços a serem 
Formação do preço de honorários contábeis em Tangará da Serra-MT: análise dos componentes do preço Adrielli Sommer Dallabona, Laércio Juarez Melz, Josiane Silva Costa dos Santos, Edineia Souza Nunes

prestados; a duração do contrato; cláusula rescisória com a fixação de prazo para a assistência, após a denúncia do contrato; honorários profissionais; prazo para seu pagamento; responsabilidade das partes e o foro para dirimir os conflitos.

A respeito do tempo de duração do contrato de serviços, deve constar uma cláusula prevendo o início do contrato, porém, ele será de prazo indeterminado quando não houver prazo estipulado no mesmo (ROKEMBACH R., 2009).

\title{
2.2 Representação da Classe Contábil
}

A classe contábil é representada pelos seus Conselhos. Por meio do Decreto-Lei 9.295 de 27 de maio de 1946, foram criados os Conselhos Federal e Regionais de Contabilidade, com a determinação de fiscalizar e reger a profissão contábil (REIS; SILVA, 2007).

Os Conselhos de Contabilidade são entidades constituídas por profissionais contábeis com várias competências legislativas, entre elas, a de registrar e fiscalizar os próprios profissionais à luz de critérios peculiares em cada caso concreto. Estes Conselhos são compostos somente de contabilistas (contadores e técnicos em contabilidade) legalmente registrados, com competência para orientar, disciplinar, fiscalizar técnica e eticamente o exercício da profissão contábil em todo o território nacional (ROCHA, 2005).

Seguindo de acordo com Rocha (2005, p. 7):

\begin{abstract}
Os conselhos atuam no registro e fiscalização profissional, sempre observando que o exercício da profissão contábil, tanto na área privada quanto na pública, constitui prerrogativa exclusiva dos contadores e dos técnicos em contabilidade, legalmente registrados no CRC de sua jurisdição, ou seja, do Estado em que vão atuar profissionalmente.
\end{abstract}

Para representar os interesses das categorias existem os sindicatos patronais e dos empregados. De acordo com Carrion (2006, p. 512), “o sindicato patronal congrega os empregadores com a finalidade de defender seus interesses econômicos".

Em Mato Grosso, o sindicato patronal da classe contábil é o Sindicato das Empresas de Serviços Contábeis, Assessoramento, Perícia e Pesquisas do Estado de Mato Grosso SESCON/MT.

Conforme o mesmo, as atividades contábeis estão voltadas em primeiro lugar, para a proteção e representação legal das categorias econômicas representadas, assim como para o assessoramento técnico. Estas atividades são realizadas através de estudos, palestras e seminários técnicos sobre assuntos de interesse da classe, e ainda, com o desenvolvimento de 
Formação do preço de honorários contábeis em Tangará da Serra-MT: análise dos componentes do preço Adrielli Sommer Dallabona, Laércio Juarez Melz, Josiane Silva Costa dos Santos, Edineia Souza Nunes

cursos e treinamentos operacionais, que são destinados à capacitação profissional dos seus colaboradores com vistas à melhora contínua dos serviços prestados aos seus clientes.

Além disso, o SESCON/MT atua na área da cooperação e assistência, caracterizada pela disponibilidade de serviços assistenciais, mediante a celebração de convênios, nas áreas da Educação, Saúde e outros serviços, para a obtenção de descontos nos valores praticados pelas empresas e entidades prestadoras de serviços.

Conforme Carrion (2006, p. 512), "o Sindicato de empregados é o agrupamento estável de membros de uma profissão, destinado a assegurar a defesa e representação da respectiva profissão para melhorar as condições de trabalho".

No caso dos escritórios contábeis, devem seguir o Sindicato dos Trabalhadores de Escritórios de Contabilidade, Assessoramento, Perícia, Advocacia, Consultoria, Auditoria, Auto Escola, Despachante, Prestadora de serviços, Temporários, Terceirizados, Pesquisas e afins - MT (SINTRAESCO).

\subsection{Convenção Coletiva de Trabalho 2012/2013}

Todo e qualquer Sindicato possui uma Convenção Coletiva de Trabalho (CCT), a qual rege e estipula sobre as condições de trabalho. A data-base para o Sindicato de Classe dos escritórios contábeis é maio. Conforme a CCT 2012/2013 do SINTRAESCO, os salários normativos para as empresas pertencentes a este Sindicato, a partir de 01/05/2012, serão da seguinte forma, com jornada de trabalho de 220 horas mensal (CONVENÇÃO..., 2012).

Tabela 1. Piso Salarial de 05/2012 à 05/2013, em R\$.

\begin{tabular}{c|c}
\hline Função & Piso Salarial \\
\hline Encarregado de Setor & $\mathrm{R} \$ 1.210,00$ \\
\hline Assistente de Setor & $\mathrm{R} \$ 1.000,00$ \\
\hline Auxiliares & $\mathrm{R} \$ 907,50$ \\
\hline Moto Boy & $\mathrm{R} \$ 798,60$ \\
\hline Auxiliar Junior & $\mathrm{R} \$ 786,50$ \\
\hline Secretária & $\mathrm{R} \$ 726,00$ \\
\hline Office Boy & $\mathrm{R} \$ 689,70$ \\
\hline Arquivista & $\mathrm{R} \$ 689,70$ \\
\hline Serviços Gerais & $\mathrm{R} \$ 622,00$ \\
\hline
\end{tabular}

Fonte: Convenção... (2012).

De acordo com a CONVENÇÃO..., (2012), “para a função de Auxiliar Junior, fica estabelecido que nos primeiros 6 meses de contrato de trabalho o salário será de $\mathrm{R} \$ 786,50$ (Setecentos e oitenta e seis reais e cinquenta centavos) e a partir do sétimo mês, passará a 
Formação do preço de honorários contábeis em Tangará da Serra-MT: análise dos componentes do preço Adrielli Sommer Dallabona, Laércio Juarez Melz, Josiane Silva Costa dos Santos, Edineia Souza Nunes

função de auxiliar com o salário de $\mathrm{R} \$$ 907,50 (Novecentos e sete reais e cinquenta centavos)".

Conforme a CONVENÇÃO..., (2012), "para os trabalhadores que perceberem acima do piso salarial estabelecido, será concedido um reajuste de $7 \%$ (sete por cento), sobre o salário do mês de Maio/11, vigendo de 01/05/2012 a 28/02/2013, compensando as antecipações salariais, de caráter geral, espontâneas concedidas no período de 01/05/2011 a 30/04/2012”.

Em seu parágrafo segundo, onde trata das diferenças salarias, as mesmas apuradas até o momento da formalização da presente convenção deverão ser quitadas em até 02 (duas) parcelas mensais, fixas e sucessivas, vencendo-se a primeira concomitantemente ao próximo vencimento salarial (CONVENÇÃO..., 2012).

\title{
2.4 Honorários contábeis
}

Honorário é a retribuição aos que exercem uma profissão liberal, a remuneração. (TREVISAN, 2012). Moreira, et al. (2010, p. 5), descreve que:

\begin{abstract}
A maior dúvida na formação do preço de venda dos administradores é saber por quanto devem ser vendidos os produtos e ou serviços para se conseguir uma lucratividade desejada. Ao pensar nisso, o preço deve ser elaborado com maior cuidado possível, pois ele influenciará no sucesso, na rentabilidade, na competitividade da empresa e, consequentemente, na sobrevivência da empresa.
\end{abstract}

Tanto o Código de Ética Profissional do Contador (Resolução CFC No. 803/96, Capítulo III, Art. $6^{\circ}$ ), quanto o CFC (2003), estabelecem alguns elementos que devem ser levados em conta na hora de estabelecer o preço de honorários contábeis (Quadro 1).

Quadro 1. Considerações relevantes para a formação de Preços de Honorários

\begin{tabular}{|l|l|}
\hline \multicolumn{1}{|c|}{ Código de Ética Profissional do Contador (1996) } & \multicolumn{1}{|c|}{ Conselho Federal de Contabilidade (2003) } \\
\hline $\begin{array}{l}\text { A relevância, o vulto, a complexidade e a dificuldade } \\
\text { do serviço a executar; }\end{array}$ & Salários pagos aos funcionários; \\
\hline $\begin{array}{l}\text { O tempo que será consumido para a realização do } \\
\text { trabalho; }\end{array}$ & Remuneração dos sócios; \\
\hline $\begin{array}{l}\text { A possibilidade de ficar impedido da realização de } \\
\text { outros serviços; }\end{array}$ & Características do serviço a ser prestado; \\
\hline $\begin{array}{l}\text { O resultado lícito favorável que para o contratante } \\
\text { advirá com o serviço prestado; }\end{array}$ & Habilidade e experiência que o trabalho exige; \\
\hline $\begin{array}{l}\text { A peculiaridade de tratar-se de cliente eventual, } \\
\text { habitual ou permanente; }\end{array}$ & Gastos gerais da empresa contábil; \\
\hline O local em que o serviço será prestado. & $\begin{array}{l}\text { Reservas destinadas a demissões de funcionários, } \\
\text { necessidade de substituição de equipamentos e } \\
\text { instalações, conservação de bens móveis e imóveis e }\end{array}$ \\
\hline
\end{tabular}


Formação do preço de honorários contábeis em Tangará da Serra-MT: análise dos componentes do preço Adrielli Sommer Dallabona, Laércio Juarez Melz, Josiane Silva Costa dos Santos, Edineia Souza Nunes

\begin{tabular}{|l|l|}
\hline & outros itens julgados; \\
\hline & Margem de lucro pretendida. \\
\hline
\end{tabular}

Fonte: CFC (1996, 2003).

A base ideal para a formação de honorários deve ser o levantamento dos custos totais por cliente, considerando os custos fixos e variáveis, para possibilitar a plena satisfação das obrigações assumidas (CFC, 2003). Para Thomé (2001 apud ZUNINO; BORGERT; SILVA, 2007), depois do custo determinado, estipular o preço de venda do serviço consiste em escolher a margem de lucro. Evidentemente, essa margem não deve ser aleatória. Convém examinar preços de mercado dos serviços semelhantes.

Apesar de não ser objetivo da pesquisa, o SESCON/MT possui uma Tabela Referencial de Honorários Profissionais, que foi elaborada em observância à exigência do Código e Defesa do Consumidor e da Legislação e Ética Profissional, cabendo ao contabilista seu reconhecimento e aplicação na execução de seus serviços. Essa tabela é sempre atualizada com base em fatores de atualização monetária de referência para a Justiça Estadual. (SESCON/MT, 2012).

\subsection{Formação do preço}

Preço é a expressão do valor de troca que se oferece por alguma coisa que satisfaça uma necessidade ou desejo. No cálculo do preço de venda, as empresas devem procurar valores que maximizem os lucros, possibilitem alcançar as metas de vendas com tal preço, permitam otimização do capital investido, e proporcionem a utilização eficaz da capacidade de produção instalada (WERNKE, 2004).

Bruni (2006, p. 231) descreve que "a formação de preços representa uma das mais importantes e nobres atividades empresariais. A definição equivocada do preço pode arruinar um negócio”. Conforme Dubois et al. (2009), a Ciência Econômica determina que a formação de preços dos bens e serviços ocorre a partir das leis da oferta e da procura.

A Lei da Oferta e da Procura busca estabilizar a procura e a oferta de um determinado bem ou serviço. Oferta é a quantidade do produto disponível em mercado, enquanto procura é o interesse existente em relação ao mesmo. A oferta depende do preço, da quantidade, da tecnologia utilizada na fabricação entre outras coisas relacionadas aos produtos e serviços. A procura é influenciada pela preferência do consumidor final, a compatibilidade entre preço e qualidade e a facilidade de compra do produto (GOMES JUNIOR, 2012). 
Formação do preço de honorários contábeis em Tangará da Serra-MT: análise dos componentes do preço Adrielli Sommer Dallabona, Laércio Juarez Melz, Josiane Silva Costa dos Santos, Edineia Souza Nunes

Para que haja uma melhor compreensão, é interessante diferenciar preço e valor. Preço é a expressão quantitativa do valor de um bem ou serviço, e irá refletir um determinado resultado da própria eficiência de produção das empresas; e o valor é subjetivo e dependerá do grau de utilidade que um bem terá para as pessoas que o consomem (DUBOIS et al. 2009, p. 221).

Alguns fatores interferem na formação do preço de venda, conforme Wernke (2004):

Quadro 2. Fatores que interferem na formação do preço de venda

Qualidade do produto diante das necessidades do mercado consumidor;

Existência de produtos similares a preços menores;

Demanda estimada do produto;

Controle de preço por órgãos reguladores;

Níveis de produção e de vendas que se pretende ou que se pode operar;

Custos e despesas de fabricar, administrar e comercializar o produto;

Níveis de produção e vendas desejadas.

Fonte: WENRKE, 2004.

Existem três processos distintos que podem ser empregados na definição de preços, e costumam basear-se nos custos, no consumidor ou na concorrência. Os processos baseados nos custos buscam, de alguma forma, adicionar algum valor aos custos. Nos processos baseados no valor percebido do produto pelo mercado consumidor, as empresas empregam a percepção que os consumidores têm do valor do produto, e não os custos do vendedor. Os baseados na concorrência, prestam atenção a seus custos ou a sua demanda, a concorrência é que determina os preços a praticar (BRUNI, 2006).

Bruni (2006) afirma, ainda, que o preço pode ser apresentado em função de seus quatro componentes: os custos (que correspondem aos gastos produtivos ou incorporados no produto), as despesas (que correspondem aos gastos não incorporados ao estoque dos produtos), os impostos (diversos são os tributos incidentes sobre o preço) e o lucro (que representa a remuneração do empresário). Ribeiro (2009, p. 505), também afirma que: "para se fixar o preço de venda de um produto, é preciso conhecer o custo da fabricação do referido produto, as despesas que serão geradas pela sua venda, o montante das despesas necessárias para administrar e financiar, e a margem de lucro desejada".

\section{METODOLOGIA}

Como primeira etapa para a elaboração do trabalho foram realizadas pesquisas bibliográficas, conforme Gil (1999), a fim de esclarecer conceitos sobre o tema. Em seguida foram apresentados conceitos de honorários contábeis e de formação de preços de venda, os 
quais também foram objetos de estudo da pesquisa. O objeto de estudo desta pesquisa foi "Critérios de Formação de Preços de Honorários Contábeis".

Esta pesquisa se caracteriza como descritiva, qualitativa e exploratória. O método principal foi a pesquisa de campo. O intuito do mesmo foi levantar os dados necessários para analisar a real forma de cobrança de honorários contábeis. O tratamento foi censitário.

A pesquisa é considerada descritiva, pois, em conformidade com Gil (1999 apud BEUREN et al., 2006, p. 81) "a pesquisa descritiva tem como principal objetivo descrever características de determinada população ou fenômeno ou o estabelecimento de relações entre as variáveis. Uma de suas características mais significativas está na utilização de técnicas padronizadas de coletas de dados".

Para realizar a coleta de dados, foi confeccionado questionário de forma clara e objetiva. No respectivo questionário continha as principais questões acerca do tema proposto, determinando as opções de respostas para que, dessa forma, fosse possível obter um resultado mais propenso à realidade.

Conforme Silva (2003, p. 57), a "pesquisa de campo consiste na coleta direta de informação no local em que acontecem os fenômenos; é a que se realiza fora do laboratório, no próprio terreno das ocorrências. Nesse tipo de pesquisa, os dados possuem objetivos preestabelecidos, discriminando suficientemente o que é coletado".

A pesquisa também possui caráter exploratório, uma vez que, apesar de existirem outras pesquisas a respeito deste tema, ele se mostra inovador por ser realizado no município de Tangará da Serra-MT, não existindo bibliografias para uso como fonte de informação. Beuren et al. (2006) descreve que a caracterização da pesquisa exploratória "normalmente ocorre quando há pouco conhecimento sobre a temática a ser abordada. Por meio do estudo exploratório, busca-se conhecer com maior profundidade o assunto, de modo a torná-lo mais claro ou construir questões importantes para a condução da pesquisa”. Silva (2003) destaca que o pesquisador pode planejar uma pesquisa exploratória para encontrar elementos necessários que lhe permitam, em contato com determinada população, obter resultados que deseja ou servir para levantar possíveis problemas de pesquisa.

A pesquisa tenta compreender os fenômenos que ocorrem para a definição do preço dos honorários contábeis. Devido a isso, considera-se o mesmo qualitativo, pois não emprega dados estatísticos no processo de análise, ou seja, não se pretende numerar as unidades de pesquisa, somente nos resultados. Richardson (1999 apud BEUREN et al., 2006, p. 91) menciona que "os estudos que empregam uma metodologia qualitativa podem descrever a 
Formação do preço de honorários contábeis em Tangará da Serra-MT: análise dos componentes do preço Adrielli Sommer Dallabona, Laércio Juarez Melz, Josiane Silva Costa dos Santos, Edineia Souza Nunes

complexidade de determinado problema, analisar a interação de certas variáveis, compreender e classificar processos dinâmicos vividos por grupos sociais”. Ainda, na pesquisa qualitativa concebem-se análises mais profundas em relação ao fenômeno que está sendo estudado, e visa destacar características não observadas por meio de um estudo quantitativo (BEUREN et al., 2006).

Em consulta realizada através da Prefeitura Municipal de Tangará da Serra-MT, foi obtido um relatório contendo todos os escritórios de contabilidade. Foi pesquisado pelo Código Nacional de Atividades Econômicas - CNAE, número 6920601. Foi obtido em primeira pesquisa (março/2012), o número de 31 escritórios. Durante o procedimento de coleta de dados, ao entregar os questionários, foi observado que havia alguns escritórios que não constavam na relação obtida. Para a confirmação e/ou conferência da mesma, foi realizada uma nova solicitação (setembro/2012), onde foi repassado outro relatório, dessa vez pesquisando pelo ramo de atividade, obtendo o número total de 40 escritórios. Dos 30 questionários que foram aplicados, foram obtidos respostas de 28 deles. Dois escritórios não devolveram os questionários respondidos, e os outros 10 escritórios não foram localizados.

\section{RESULTADOS}

Esta seção apresenta os resultados obtidos com esta pesquisa. Os mesmos apresentamse em tabelas, de acordo com as respostas dos entrevistados. Ao total, foram respondidos 28 questionários pelos escritórios de contabilidade da cidade, os quais forneceram informações de suma importância para o desenvolvimento do resultado desta pesquisa. Diante dos resultados obtidos, a partir dos questionários aplicados, foi possível identificar o perfil dos entrevistados com as questões de 1 a 4 (tabelas 2 e 3 ).

A tabela 2 representa o sexo e a faixa etária dos entrevistados. De acordo com o que foi levantado, pode-se observar que a maioria é do sexo masculino, correspondendo a 71,43\%. Apenas 3,57\% deles possuem de 21 a 30 anos, 25\% de 31 a 40 anos, e os 42,86\% restantes possuem acima dos 40 anos de idade. Foi possível observar, também, que a maioria dos entrevistados (homens e mulheres) estão com a faixa etária acima dos 40 anos, 57,14\% do total. Seguido dos que possuem de 31 a 40 anos, com 35,72\%, e de quem possui de 21 a 30 anos, com apenas $7,14 \%$.

Tabela 2 - Sexo e Faixa Etária dos entrevistados.

\begin{tabular}{l|c|c|r|r}
\hline \multicolumn{1}{c|}{ Qual o seu sexo? } & De 21 a 30 anos & De 31 a 40 anos & Acima de 40 anos & Total Geral \\
\hline \multicolumn{4}{|c}{} & Revista UNEMAT de Contabilidade \\
\hline Volume 2, Número 3 & 16 & ISSN: 2316-8072 \\
Jan./Jun. 2013 & &
\end{tabular}


Formação do preço de honorários contábeis em Tangará da Serra-MT: análise dos componentes do preço Adrielli Sommer Dallabona, Laércio Juarez Melz, Josiane Silva Costa dos Santos, Edineia Souza Nunes

\begin{tabular}{c|c|c|c|c}
\hline Feminino & $3,57 \%$ & $10,71 \%$ & $14,29 \%$ & $\mathbf{2 8 , 5 7 \%}$ \\
\hline Masculino & $3,57 \%$ & $25,00 \%$ & $42,86 \%$ & $\mathbf{7 1 , 4 3 \%}$ \\
\hline Total Geral & $\mathbf{7 , 1 4 \%}$ & $\mathbf{3 5 , 7 2 \%}$ & $\mathbf{5 7 , 1 4 \%}$ & $\mathbf{1 0 0 , 0 0 \%}$ \\
\hline
\end{tabular}

A tabela 3 representa a formação e a especialização dos entrevistados. No que diz respeito à formação dos mesmos, foi possível observar que a maioria eram contadores, somando $71,43 \%$, e os $28,57 \%$ restantes são apenas técnicos em contabilidade. Um dos entrevistados que é técnico, possui outra formação, advogado.

Pode-se observar que mais da metade dos entrevistados não possuía especialização, somando $53,57 \%$. O percentual restante estava divido para os que possuem pós-graduação, com $32,14 \%$, para quem possui outro tipo de especialização além das perguntadas, $10,72 \%$. Somente uma pessoa indicou que estava fazendo mestrado.

Com relação à formação do preço de venda de seus serviços, como dito anteriormente, deve ser levado em consideração os custos e os gastos da empresa, pois é através dos honorários que a empresa irá manter esses respectivos gastos. Para alguém especializado, fica muito mais fácil conciliar o pagamento das contas com o ganho (honorários), ou seja, na hora do rateio.

Toda especialização é válida, porém, deve ser observado em qual área a pessoa vai trabalhar, pois não adiantará muita coisa, ou seja, não servirá muito o conhecimento adquirido, se essa pessoa trabalha com departamento pessoal por exemplo, e ser especialista em auditoria. Para a formação do preço dos honorários, a especialização mais aconselhável é da área de custos.

Tabela 3 - Formação e Especialização dos entrevistados.

\begin{tabular}{c|c|c|c|c|c}
\hline Qual a sua formação? & Não possui & Outro & Pós Graduação & $\begin{array}{c}\text { Pós Graduação e } \\
\text { Mestrando }\end{array}$ & $\begin{array}{c}\text { Total } \\
\text { Geral }\end{array}$ \\
\hline Contador & $32,14 \%$ & $7,14 \%$ & $28,57 \%$ & $3,57 \%$ & $\mathbf{7 1 , 4 3 \%}$ \\
\hline $\begin{array}{c}\text { Técnico em } \\
\text { Contabilidade }\end{array}$ & $21,43 \%$ & $0,00 \%$ & $3,57 \%$ & $0,00 \%$ & $\mathbf{2 5 , 0 0 \%}$ \\
\hline $\begin{array}{c}\text { Técnico em } \\
\text { Contabilidade e } \\
\text { Advogado }\end{array}$ & $0,00 \%$ & $3,57 \%$ & $0,00 \%$ & $0,00 \%$ & $\mathbf{3 , 5 7 \%}$ \\
\hline Total Geral & $\mathbf{5 3 , 5 7 \%}$ & $\mathbf{1 0 , 7 2 \%}$ & $\mathbf{3 2 , 1 4 \%}$ & $\mathbf{3 , 5 7 \%}$ & $\mathbf{1 0 0 , 0 0 \%}$ \\
\hline
\end{tabular}

As tabelas 4 e 5 são correlacionadas, pois tratam do início das atividades (da abertura) dos escritórios, e do tempo de atuação dos entrevistados na área da contabilidade. De acordo com a pesquisa efetuada, os dois primeiros escritórios de contabilidade da cidade iniciaram suas atividades no ano de 1974 e o escritório mais recente é de 2011 (tabela 4). Pode-se 
Formação do preço de honorários contábeis em Tangará da Serra-MT: análise dos componentes do preço Adrielli Sommer Dallabona, Laércio Juarez Melz, Josiane Silva Costa dos Santos, Edineia Souza Nunes

observar também que o período que mais se abriu escritórios na cidade foi de 1998 a 2002, totalizando 6 escritórios, $21,43 \%$ dos entrevistados.

Tabela 4 - Início das atividades dos escritórios.

\begin{tabular}{c|c}
\hline A sua empresa está em atividade desde quando? & Total \\
\hline De 1973 a 1977 & $7,14 \%$ \\
\hline De 1983 a 1987 & $14,29 \%$ \\
\hline De 1988 a 1992 & $10,71 \%$ \\
\hline De 1993 a 1997 & $7,14 \%$ \\
\hline De 1998 a 2002 & $21,43 \%$ \\
\hline De 2003 a 2007 & $17,86 \%$ \\
\hline De 2008 a 2012 & $17,86 \%$ \\
\hline Não respondeu & $3,57 \%$ \\
\hline Total Geral & $\mathbf{1 0 0 , 0 0 \%}$ \\
\hline
\end{tabular}

Com relação ao tempo de atuação desses profissionais no mercado de trabalho, a maioria está atuando a mais de 10 anos na área da contabilidade, correspondendo a 78,57\%. Nota-se que a quantidade de pessoas que iniciaram as atividades na área da contabilidade recentemente é mínima, somando 3,57\% da totalidade (tabela 5).

O trabalho de um profissional pode ser reconhecido por diversos fatores, um deles é o tempo de atuação no mercado de trabalho. Mas afinal, o que leva um escritório de contabilidade permanecer por tanto tempo no mercado de trabalho? Muitos clientes estão indo atrás de empresas que possuam um diferencial competitivo, que hoje, é voltado para a área da responsabilidade social, onde esses clientes procuram escritórios de contabilidade que desenvolvam projetos voltados para esse aspecto. Com o passar dos anos os escritórios vão ganhando reconhecimento por parte da população, ganha credibilidade perante os clientes, isso é devido ao fato de prestarem um bom serviço, um serviço de qualidade, e isso justifica a permanência do mesmo no mercado.

Tabela 5 - Tempo de atuação dos entrevistados.

\begin{tabular}{c|c}
\hline Qual o seu tempo de atuação na área? & Total \\
\hline De 3 a 5 anos & $3,57 \%$ \\
\hline De 5 a 10 anos & $14,29 \%$ \\
\hline Mais de 10 anos & $78,57 \%$ \\
\hline Menos de 2 anos & $3,57 \%$ \\
\hline Total Geral & $\mathbf{1 0 0 , 0 0 \%}$ \\
\hline
\end{tabular}

Comparando o início das atividades dos escritórios com o tempo de atuação dos entrevistados na área (tabelas 4 e 5), encontra-se uma divergência. Para estar atuando no mercado de trabalho a mais de 10 anos, o escritório deveria ter iniciado suas atividades antes 
Formação do preço de honorários contábeis em Tangará da Serra-MT: análise dos componentes do preço Adrielli Sommer Dallabona, Laércio Juarez Melz, Josiane Silva Costa dos Santos, Edineia Souza Nunes

de 2002. Observando a tabela 4, nota-se que a quantidade de escritórios abertos nesse período foi 17 (60,71\%). Portanto, apenas esses 17 escritórios estão em atividade a mais de 10 anos, e não os $22(78,57 \%)$ como demonstra a tabela 5. A suposição feita foi: que os questionários foram respondidos levando em consideração os anos em que os entrevistados trabalhavam como empregados também, e não somente o tempo de atividade como donos e/ou sócios do referido escritório.

O quadro de funcionários dos escritórios diz muito em relação à pesquisa. São os funcionários que realizam as rotinas relacionadas aos serviços. Considerando isso, foi pesquisada a composição do quadro de funcionários nos escritórios contábeis do município de Tangará da Serra-MT. A tabela 6 apresenta o número de escritórios que possuem entre 0 e mais de 10 funcionários, separados por funções. A coluna 'não há' representa o número de escritórios no qual não há nenhum funcionário na função. Pode-se observar que o cargo mais ocupado é o de encarregado de setor. Encarregados são as pessoas que respondem por determinado setor dentro da empresa. Do total, 22 escritórios têm funcionários nesse cargo. Em seguida vem o cargo de auxiliares de setor, presente em 20 escritórios. O cargo menos ocupado é o de auxiliar júnior, existente em apenas um escritório, sendo 3 funcionários ocupando o referido cargo.

Tabela 6 - Resposta à questão: Quantos funcionários trabalham na empresa? Em quantidade de escritórios para cada número de funcionários entre 0 e acima de 10.

\begin{tabular}{|c|c|c|c|c|c|c|c|c|c|c|c|c|}
\hline \multirow[b]{2}{*}{ Função } & \multicolumn{12}{|c|}{ Número de Funcionários } \\
\hline & $\begin{array}{l}\text { Não } \\
\text { há }\end{array}$ & 1 & 2 & 3 & 4 & 5 & 6 & 7 & 8 & 9 & 10 & $\begin{array}{l}\text { Acima de } 10 \\
\text { funcionários }\end{array}$ \\
\hline Encarregado de Setor & 6 & 5 & 10 & 4 & 2 & 0 & 1 & 0 & 0 & 0 & 0 & 0 \\
\hline Auxiliares & 8 & 3 & 6 & 4 & 0 & 1 & 1 & 2 & 2 & 0 & 0 & 1 \\
\hline Secretária & 14 & 14 & 0 & 0 & 0 & 0 & 0 & 0 & 0 & 0 & 0 & 0 \\
\hline Assistente de Setor & 15 & 5 & 2 & 1 & 1 & 1 & 1 & 2 & 0 & 0 & 0 & 0 \\
\hline Office Boy & 15 & 13 & 0 & 0 & 0 & 0 & 0 & 0 & 0 & 0 & 0 & 0 \\
\hline Moto Boy & 16 & 12 & 0 & 0 & 0 & 0 & 0 & 0 & 0 & 0 & 0 & 0 \\
\hline Arquivista & 22 & 4 & 2 & 0 & 0 & 0 & 0 & 0 & 0 & 0 & 0 & 0 \\
\hline Auxiliar Junior & 27 & 0 & 0 & 1 & 0 & 0 & 0 & 0 & 0 & 0 & 0 & 0 \\
\hline
\end{tabular}

A tabela 7 apresenta os serviços prestados pelos escritórios. Mais precisamente para quem são realizados esses serviços, se é para apenas os clientes regulares, para demais pessoas e/ou empresas (clientes eventuais), ou para ambas (clientes regulares e clientes eventuais). Por meio dos resultados obtidos, pode-se observar que a maioria dos escritórios prestam os serviços citados abaixo para os clientes regulares. Porém, um serviço se destacou por ser prestado para ambos, que foi a declaração do Imposto de Renda de Pessoa Física, com $46,43 \%$ da totalidade do serviço. 
Formação do preço de honorários contábeis em Tangará da Serra-MT: análise dos componentes do preço Adrielli Sommer Dallabona, Laércio Juarez Melz, Josiane Silva Costa dos Santos, Edineia Souza Nunes

Tabela 7 - Serviços executados para clientes regulares e/ou eventuais, em \%.

\begin{tabular}{c|c|c|c|c|c}
\hline Função & $\begin{array}{c}\text { Cliente } \\
\text { Regular }\end{array}$ & $\begin{array}{c}\text { Cliente } \\
\text { Eventual }\end{array}$ & Ambos & $\begin{array}{c}\text { Não } \\
\text { Informou }\end{array}$ & $\begin{array}{c}\text { Total } \\
\text { Geral }\end{array}$ \\
\hline Escrituração contábil, fiscal e de pessoal. & 67,86 & 7,14 & 3,57 & 21,43 & $\mathbf{1 0 0 , 0 0}$ \\
\hline Escrituração do livro caixa. & 64,29 & 14,29 & 3,57 & 17,86 & $\mathbf{1 0 0 , 0 0}$ \\
\hline Serviços societários (constituição e outras operações). & 78,57 & 3,57 & 7,14 & 10,71 & $\mathbf{1 0 0 , 0 0}$ \\
\hline Perícias judiciais e extrajudiciais. & 25,00 & 32,14 & 7,14 & 35,71 & $\mathbf{1 0 0 , 0 0}$ \\
\hline Auditoria Contábil. & 28,57 & 28,57 & 3,57 & 39,29 & $\mathbf{1 0 0 , 0 0}$ \\
\hline Consultoria, assessoria e pareceres. & 42,86 & 21,43 & 10,71 & 25,00 & $\mathbf{1 0 0 , 0 0}$ \\
\hline Imposto de Renda de pessoa física. & 39,29 & 3,57 & 46,43 & 10,71 & $\mathbf{1 0 0 , 0 0}$ \\
\hline Certidões. & 60,71 & 10,71 & 7,14 & 21,43 & $\mathbf{1 0 0 , 0 0}$ \\
\hline Cadastro Bancário (pessoa física e/ou jurídica). & 75,00 & 3,57 & 3,57 & 17,86 & $\mathbf{1 0 0 , 0 0}$ \\
\hline Cadastro de admissão e demissão de funcionários. & 75,00 & - & 3,57 & 21,43 & $\mathbf{1 0 0 , 0 0}$ \\
\hline Elaboração anual de rais negativa. & 67,86 & - & 10,71 & 21,43 & $\mathbf{1 0 0 , 0 0}$ \\
\hline RAIS. & 71,43 & - & 7,14 & 21,43 & $\mathbf{1 0 0 , 0 0}$ \\
\hline SINTEGRA. & 75,00 & - & 3,57 & 21,43 & $\mathbf{1 0 0 , 0 0}$ \\
\hline GIA. & 71,43 & 3,57 & 7,14 & 17,86 & $\mathbf{1 0 0 , 0 0}$ \\
\hline DACON. & 67,86 & 3,57 & 3,57 & 25,00 & $\mathbf{1 0 0 , 0 0}$ \\
\hline DCTF. & 71,43 & - & 7,14 & 21,43 & $\mathbf{1 0 0 , 0 0}$ \\
\hline SPED - FISCAL. & 75,00 & - & 3,57 & 21,43 & $\mathbf{1 0 0 , 0 0}$ \\
\hline SPED - CONTÁBIL. & 64,29 & - & 3,57 & 32,14 & $\mathbf{1 0 0 , 0 0}$ \\
\hline SPED - PIS E COFINS. & 67,86 & - & 3,57 & 28,57 & $\mathbf{1 0 0 , 0 0}$ \\
\hline DIRF. & 64,29 & 3,57 & 10,71 & 21,43 & $\mathbf{1 0 0 , 0 0}$ \\
\hline
\end{tabular}

O honorário é a fonte de renda dos escritórios, pois é através deles que a empresa consegue manter o seu quadro de funcionários, pagar os impostos, as despesas, dentre outros. Baseado nisso, foi verificado qual a forma de pagamento que os escritórios oferecem aos seus clientes. Pode-se analisar que não é utilizada uma forma de pagamento específica, ou seja, é oferecida mais de uma possibilidade para se efetuar o pagamento dos honorários, para que seus clientes possam escolher a que melhor lhes convém. As formas de pagamento mais utilizadas pelos escritórios são o boleto bancário, com 32,14\% da totalidade, e o dinheiro, com $25 \%$ (tabela 8).

Tabela 8 - Forma de pagamento que os escritórios proporcionam.

\begin{tabular}{c|c}
\hline Qual forma de pagamento você proporciona aos seus clientes? & Total \\
\hline Boleto Bancário & $32,14 \%$ \\
\hline Dinheiro & $25,00 \%$ \\
\hline Boleto e Dinheiro & $17,86 \%$ \\
\hline Não respondeu & $7,14 \%$ \\
\hline Todas & $3,57 \%$ \\
\hline Outra: Cobrança & $3,57 \%$ \\
\hline Boleto, Dinheiro e Outra (Cheque) & $3,57 \%$ \\
\hline Dinheiro e Outra: (Cheque) & $3,57 \%$ \\
\hline Dinheiro e Cartão & $3,57 \%$ \\
\hline Total Geral & $\mathbf{1 0 0 , 0 0 \%}$ \\
\hline
\end{tabular}


Formação do preço de honorários contábeis em Tangará da Serra-MT: análise dos componentes do preço Adrielli Sommer Dallabona, Laércio Juarez Melz, Josiane Silva Costa dos Santos, Edineia Souza Nunes

Para finalizar a pesquisa, foi levantada a questão com relação aos critérios utilizados para a formação do preço dos respectivos honorários, e qual o grau de importância dos mesmos. Para isso, foram utilizados como base os fatores expostos pelo Código de Ética Profissional do Contador e pelo Conselho Federal de Contabilidade, conforme apresentado no quadro 1. A resposta obtida através dos questionários, o critério que possui maior relevância para os escritórios na hora da formação do preço de seus honorários é a relevância, o vulto, a complexidade e a dificuldade do serviço a executar, como se pode observar na tabela 9.

Considerando os graus 0 e 1 como nada ou pouco importante, os graus 2 e 3 como regular, e os graus 4 e 5 como mais relevantes, o resultado da pesquisa seria outro. Neste caso, seria o tempo consumido para a realização do trabalho o fator determinante da formação do preço dos honorários, considerando $12+13$ respostas 4 e 5 (importante e muito importante). Em análise mais profunda, os fatores 'complexidade' e 'tempo' estão relacionadas. Quanto maior a complexidade e dificuldade do serviço, maior seria o tempo para execução do mesmo.

Tabela 9 - Resposta à questão: Atribua uma nota de 0 a 5 pelo grau de importância dos critérios abaixo na formação do preço de honorários.

\begin{tabular}{r|c|c|c|c|c|c}
\hline Critérios & $\mathbf{0}$ & $\mathbf{1}$ & $\mathbf{2}$ & $\mathbf{3}$ & $\mathbf{4}$ & $\mathbf{5}$ \\
\hline A relevância, o vulto, a complexidade e a dificuldade do serviço a executar. & 0 & 1 & 1 & 5 & 4 & 17 \\
\hline Habilidade e experiência que o trabalho exige. & 1 & 1 & 0 & 5 & 6 & 15 \\
\hline O tempo que será consumido para a realização do trabalho. & 0 & 0 & 0 & 3 & 12 & 13 \\
\hline Características do serviço a ser prestado. & 0 & 0 & 1 & 5 & 9 & 13 \\
\hline A peculiaridade de tratar-se de cliente eventual habitual ou permanente. & 0 & 2 & 4 & 4 & 7 & 11 \\
\hline O resultado lícito favorável que para o contratante advirá com o serviço prestado. & 2 & 0 & 3 & 6 & 7 & 10 \\
\hline Gastos gerais da empresa contábil. & 3 & 0 & 4 & 6 & 6 & 9 \\
\hline A possibilidade de ficar impedido da realização de outros serviços. & 3 & 2 & 1 & 5 & 9 & 8 \\
\hline Margem de lucro pretendida. & 3 & 0 & 3 & 6 & 8 & 8 \\
\hline O local em que o serviço será prestado. & 1 & 5 & 1 & 7 & 6 & 8 \\
\hline Salários pagos aos funcionários. & 2 & 1 & 2 & 4 & 13 & 6 \\
\hline $\begin{array}{c}\text { Reservas destinadas a demissões de funcionários, necessidade de substituição de } \\
\text { equipamentos e instalações, conservação de bens móveis e imóveis e outros itens } \\
\text { julgados. }\end{array}$ & 3 & 4 & 1 & 8 & 6 & 6 \\
\hline Remuneração dos sócios. & & & & \\
\hline
\end{tabular}

\section{CONCLUSÃO}

Em resposta ao problema da pesquisa, observou-se pela exposição do trabalho e da pesquisa de campo que, levando em consideração o grau de importância 5 e, avaliando as respostas desse grau como as mais importantes, o fator pelo qual os escritórios dão mais importância na formação do preço de honorários é a relevância, o vulto, a complexidade e a dificuldade do serviço a executar. 
Formação do preço de honorários contábeis em Tangará da Serra-MT: análise dos componentes do preço Adrielli Sommer Dallabona, Laércio Juarez Melz, Josiane Silva Costa dos Santos, Edineia Souza Nunes

Em relação aos objetivos da pesquisa, foram todos atingidos. O objetivo geral foi alcançado, pois foi possível identificar os critérios de formação de honorários contábeis nos escritórios contábeis da cidade. Em relação aos objetivos específicos, todos foram alcançados, começando com a amostra da pesquisa, sendo realizada em 28 escritórios, do total de 40, conforme dados obtidos na Prefeitura Municipal de Tangará da Serra-MT.

Seguindo, os fatores influenciadores dos preços de venda de serviços podem ser observados conforme o quadro 2, extraído de Wernke (2004). Levando em consideração a importância desses fatores, assim como os fatores expostos do quadro 1, quais deles são caracterizados como mais importantes, através dos resultados da pesquisa pode-se identificar que são a relevância, o vulto, a complexidade e a dificuldade, ou seja, qual a complexidade e dificuldade do serviço, conforme observado através da tabela 9.

Com relação ao último objetivo específico, comparar as características e os critérios estabelecidos pelos escritórios para formar o preço de seus honorários, é possível identificar os critérios que mais são levados em consideração. $O$ três principais são: $1^{\circ}$ ) a relevância, o vulto, a complexidade e a dificuldade do serviço a executar; $2^{\circ}$ ) habilidade e experiência que o trabalho exige; $3^{\circ}$ ) o tempo que será consumido para a realização do trabalho.

Quanto à limitação da pesquisa, ela se limitou na cidade de Tangará da Serra-MT, pesquisando apenas os escritórios de contabilidade da mesma. Os questionários foram respondidos apenas pelos donos e/ou sócios dos escritórios, não se abrindo aos funcionários dos mesmos, não sendo possível generalizar os resultados em nível regional ou nacional.

\section{REFERÊNCIAS}

BEUREN, I. M. et al. Como elaborar trabalhos monográficos em contabilidade. $2^{\mathrm{a}}$ edição. São Paulo: Atlas, 2006.

BRASIL. Casa Civil. Lei no 10.406, de 10 de janeiro de 2002: institui o Código Civil. Disponível em: <http://www.planalto.gov.br/ccivil_03/leis/2002/L10406.htm>. Acesso em: 24 mar. 2012, 16:26:18.

BRUNI, A. L. A administração de custos, preços e lucros. São Paulo: Atlas, 2006.

CARRION, V. Comentários à Consolidação das Leis do Trabalho. $31^{\mathrm{a}}$ edição. São Paulo: Saraiva, 2006.

CFC, Conselho Federal de Contabilidade. Resolução CFC Nº 987/2003: regulamenta a obrigatoriedade do contrato de prestação de serviços contábeis e dá outras providências. Disponível em: <http://www.portaldecontabilidade.com.br/nbc/res987.htm>. Acesso em: 11 mar. 2012, 16:22:46. 
Resolução CFC No. 1373/11: regulamenta o exame de suficiência como requisito para obtenção ou restabelecimento de registro profissional em Conselho Regional de Contabilidade (CRC). Disponível em:

<http://www.crcsp.org.br/portal_novo/legislacao_contabil/resolucoes/Res1373.htm>. Acesso em: 14 abr. 2012, 15:18:47.

. Resolução CFC No 803/96: Aprova o Código de Ética Profissional do Contador -

CEPC. Disponível em: <http://www.cfc.org.br/sisweb/sre/docs/RES_803.doc〉. Acesso em 21 out. 2012.

CONVENÇÃO Coletiva de Trabalho 2012/2013. 2012. Disponível em:

<http://www3.mte.gov.br/internet/mediador/relatorios/ImprimirICXML.asp?NRRequeriment o=MR026156/2012 >. Acesso em: 25 ago. 2012, 15:43:17.

DUBOIS, A. et al. Gestão de custos e formação de preços. São Paulo: Atlas, 2009.

DUFFECKE, R. A importância do contrato de prestações de serviços contábeis. Paraná, 2007.

GOMES JUNIOR, W. R. Lei da oferta e da procura. Disponível em:

<http://www.administradores.com.br/informe-se/artigos/lei-da-oferta-e-procura/36090/>. Acesso em: 27 abr. 2012, 11:26:45.

HANSEN, D. R.; MOWEN, M. M. Gestão de custos: contabilidade e controle. $3^{\text {a }}$ edição. São Paulo: Pioneira Thonson Learning, 2001.

MOREIRA, C. A. et al. Custo da prestação de serviços contábeis: o caso da Casintep Contabilidade e Assessoria Ltda., uma organização contábil do município de Sinop-MT. Revista Contabilidade \& Amazônia, Sinop-MT, v. 3, n. 1, 2010.

REIS, A. J.; SILVA, S. L. da. A história da contabilidade no Brasil. 2007.

RIBEIRO, O. M. Contabilidade de custos. São Paulo: Saraiva, 2009.

ROCHA, J. C. F. Manual do contabilista: uma abordagem teórico-prática da profissão contábil. São Paulo: Saraiva, 2005.

ROKEMBACH, R. As organizações contábeis e o contrato de prestação de serviços. Rio Grande do Sul, jan. 2009.

SESCON/MT, Sindicato das Empresas de Serviços Contábeis, Assessoramento, Perícias, Informações e Pesquisas de Mato Grosso. Apresentação do SESCON-MT. Disponível em: $<\mathrm{http}: / / \mathrm{www}$. sescon-mt.com.br/?p=noticia\&codigo=1142>. Acesso em: 20 mar. 2012, $12: 17: 32$.

Sindicato do SESCON-MT. Disponível em: <http://www.sescon$\mathrm{mt} . \mathrm{com} . \mathrm{br} / \mathrm{p}=\mathrm{sessao} \&$ tipo $=\mathrm{O} \% 20$ sindicato $>$. Acesso em: 20 mar. 2012, 12:08:31.

Tabela de Honorários SESCON-MT. Disponível em: <http://www.sesconmt.com.br/TABELAdeHonorariosContabeis2011.pdf >. Acesso em: 10 mar. 2012, 14:15:27. 
SILVA, A. C. R. da. Metodologia da pesquisa aplicada à contabilidade. São Paulo: Atlas, 2003.

WERNKE, R. Gestão de custos: uma abordagem prática. São Paulo: Atlas, 2004.

ZUNINO, A.; BORGERT, A.; SILVA, M. Z. da. Mensuração e determinação do preço de serviços: um estudo com profissionais liberais em Florianópolis/SC. In: XXVII Encontro Nacional de Engenharia de Produção (ENEGEP), Foz do Iguaçu, 09 a 11 de outubro de 2007. 